\section{Research Campus ARENA2036}

The innovation platform for mobility and production of the future

The Research Campus ARENA2036 is a novel co-creative innovation environment. The proximity of researchers and developers from more than 50 partners within the $10,000 \mathrm{~m}^{2}$ research factory enables higher speeds on the way from idea, to project, to transfer. Dr Clemens Ackermann, research coordinator at ARENA2036, explains that the goal of the Research and applied research - to produce potentially disruptive and leap-frog innovations and to transfer them to industry.

RENA2036 (the Active Research
Environment for the Next
Generation of Automobiles) is a

a platform where more than 50 partners from industry and science are collaborating, exchanging ideas, and trying out new concepts in a precompetitive environment. In addition to Research Campus founded by, among others, Daimler AG, Robert Bosch the University of Stuttgart, providing a unique collaborative environment that enables industry and academia to work together on future-oriented topics. Named in anticipation of 2036 this innovation platform marks the 50th anniversary of the automobile as it provides sustanhlie automotive

Dr Clemens Ackermann and Peter Froeschle from ARENA2036, together with Manuel Fechter from Fraunhofer IPA, discuss how ARENA2036 provides business location Baden-Württemberg already renowned for its automotive industry, the seamless transfer of research results into industrial application facilitates the creation of innovative business models, particularly for small and medium enterprises (SMEs).

\section{INTERDISCIPLINARY APPROACH} Underpinned by its excellent applied research, ARENA2036 to produce potentially disruptive and leap-frog innovations that can be

transferred to industry and contribute to the transformation of work, mobility, and production. With partners in various disciplines such as aerospace and mogerials research, as well as the automotive industry, Dr Ackerma explains that the interdisciplinary and trans-institutional approach of the various fields is an essential compon of the Research Campus. This interdisciplinary linking of the diverse stakeholders is reflected in the close cooperation of all actors under the umbrella of ARENA2036.

Moreover, the proximity of researchers and developers from more than 50 partners within the $10,000 \mathrm{~m}^{2}$ research factory shortens the interval between the conception of an idea and its transfer trakeholders and combining various stakeholders and their ideas is of great the ARENA2036 Research Campus is the sharing of risk among all participants. This creates an opportunity to research issues that do not necessarily have to be included in the next model cycle, as they can potentially' 'reach far into this century' (Ackermann, Fechter \& Froeschle, 2021).

\title{
INDUSTRY 4.0
}

The Fourth Industrial Revolution, known as Industry 4.0, has emerged with the emphasis on taking digital technology to a new level. Originating as a national strategic initiative from the German government, it focuses on driving digital manufacturing forward by increasing digitisation and the interconnection of products, value
chains, and business models. It is also encouraging the networking of industry Uring (loT) into manufacturing with the ongoing automation of manufacturing and industrial practices. Intelligent manufacturing environments are proposed through the development and implementation of Cyber-Physical Production Systems made up of cooperative independent elements that are integrated into the Industrial Interne of Things to create Smart Factories. ARENA2036 is setting the pace for Industry 4.0, offering an interlinked and holistic approach to manfacturing.

DATA INTEROPERABILITY The partners are using common communication paranderdised data interoperability and transparency. They are also employing uniform information models and semantic parameters to describe various application demands within the automotive industry use-case. Asset administration shells, in the form of standardised interfaces, exten the conventional physical assets to interconnected production. Data for all products and production resources are potentially accessible to every user and asset within the ARENA2036 Research Campus. In providing both data transparency and interoperability, ARENA2036 is a abling new data-diven business models in smart production as properties in the product domain.

Researchers are also exploring data interoperability within the domains of product development and production system design, aiming to significantly reduce the time taken by product development and market introduction. This has particular importance for the ongoing transformation processes with the automotive industry that require increasingly flexible manufacturing processes. These are characterised by the incorporation of new product and production technologies into serial production at ever shorter intervals and prestim anse challenges for product design alongside corresponding
production systems.

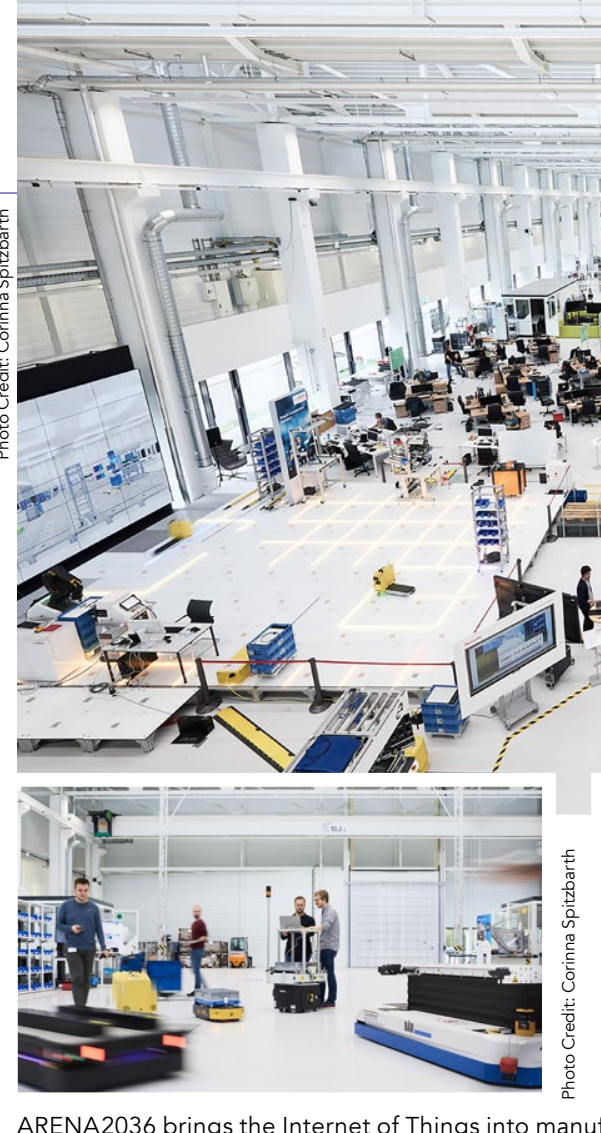

HOLISTIC SEMANTIC MODELLING DrAckermann describes how the basic ideas of innovation design incorporated at the Research Campus ARENA2036 offer a platform for joint research in a pre-competitive environment. These joint research projects are the foundation of ARENA2036 and enable all partners to pave the way for the mobility of the future. The holistic semantic modelling development, particularly in the joint research projects Fluid Production

The interdisciplinary and transinstitutional approach of the various fields is an essential component of the Research Campus.

this. Furthermore, these projects demonstrate an approach to production that emphasises the need for constant (n) role of humans as designers of their production environments.

CYBER-PHYSICAL PRODUCTION SYSTEMS: FLUID PRODUCTION the challenges confronting production engineering design reging product planning, configuration and investment
Production enables the system, design and set-up to be moved as close as possible to the start of production, thereby minimising the uncertainties and applied technologies. It also reduces possible discrepancies between product design and production.

Fluid Production involves all production facilities being broken down into location-flexible modules. These anthropocentric focus so that, with 


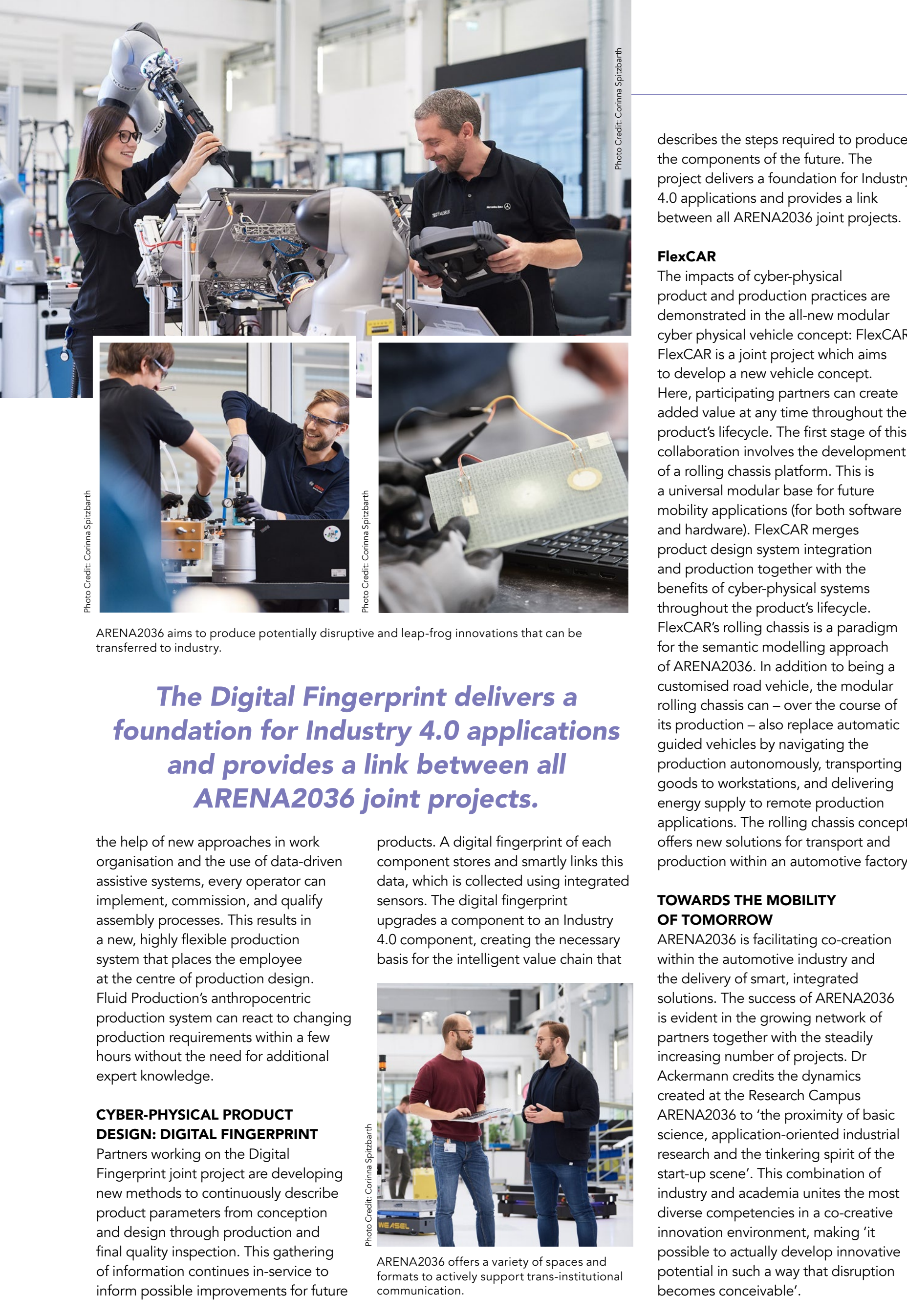

\section{Behind the Research}

Dr Clemens

Ackermann

E: clemens.ackermanne
arena2036.de $+491754385589$

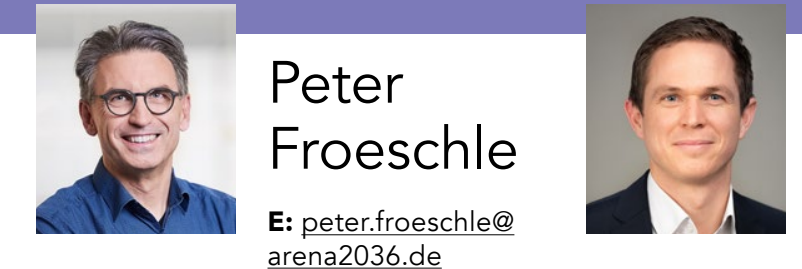

Manuel

Fechter

W: www.arena2036.de/en in www.linkedin.com/company/arena2036

Research Objectives

The Research Campus ARENA2036 is a novel co-creative environment that enables innovative research and the seamless transfer of research results into industrial applications.

\section{Detail}

Address

Dr Clemens Ackerman

Pfaffenwaldring 19

70569 Stuttgart

Germany

Bio

Dr Clemens Ackermann has worked as a research coordinator at deputy managing director, since 2017. Before joining ARENA2036,

he taught at numerous universities and universities of applied sciences

\begin{tabular}{|c|c|}
\hline $\begin{array}{l}\text { in Germany and abroad. He } \\
\text { received his PhD from Northwestern }\end{array}$ & $\begin{array}{l}\text { Manuel Fechter studied mechanical } \\
\text { engineering at RWTH Aachen }\end{array}$ \\
\hline University, Illinois. & $\begin{array}{l}\text { University. Starting in } 2014 \text {, he } \\
\text { worked as research associate and }\end{array}$ \\
\hline $\begin{array}{l}\text { Peter Froeschle is the managing } \\
\text { director of the Research Campus }\end{array}$ & $\begin{array}{l}\text { Head of Business Unit Automotive } \\
\text { in the area of human-robot }\end{array}$ \\
\hline $\begin{array}{l}\text { director of the Research Campus } \\
\text { ARENA2036 and co-founder of }\end{array}$ & $\begin{array}{l}\text { in the area of human-robot } \\
\text { collaboration and new production }\end{array}$ \\
\hline $\begin{array}{l}\text { ARENAZU6 and co-founder of } \\
\text { the start-up accelerator STARTUP }\end{array}$ & concepts at Fraunhofer Institute \\
\hline $\begin{array}{l}\text { AUTOBAHN. Previously, he worked } \\
\text { in development at Daimler AG. }\end{array}$ & for Production Engineering and \\
\hline Among other things, he was & Automation IFA and AREINAZUS6. \\
\hline responsible for Strategic Energy & Funding \\
\hline Projects \& Market Development Fuel & The Federal Ministry of Education a \\
\hline Cell / EV. & Research, Germany (BMBF) \\
\hline
\end{tabular}

Personal Response

What is the most significant development to date that will shape the mobility of the future?

II Surely, the diffusion of 'mobility as a service' has a major impact on the mobility of the future. To begin with, it changes the product development process, the production, and the scenarios for use, since the final product - and the OEMs accordingly - will eventually have to master the tight-rope walk between individual and institutional customers. Even the individual customer, who demands ever higher degrees of customisability, slowly gravitates towards highly flexible, needs-based solutions. II

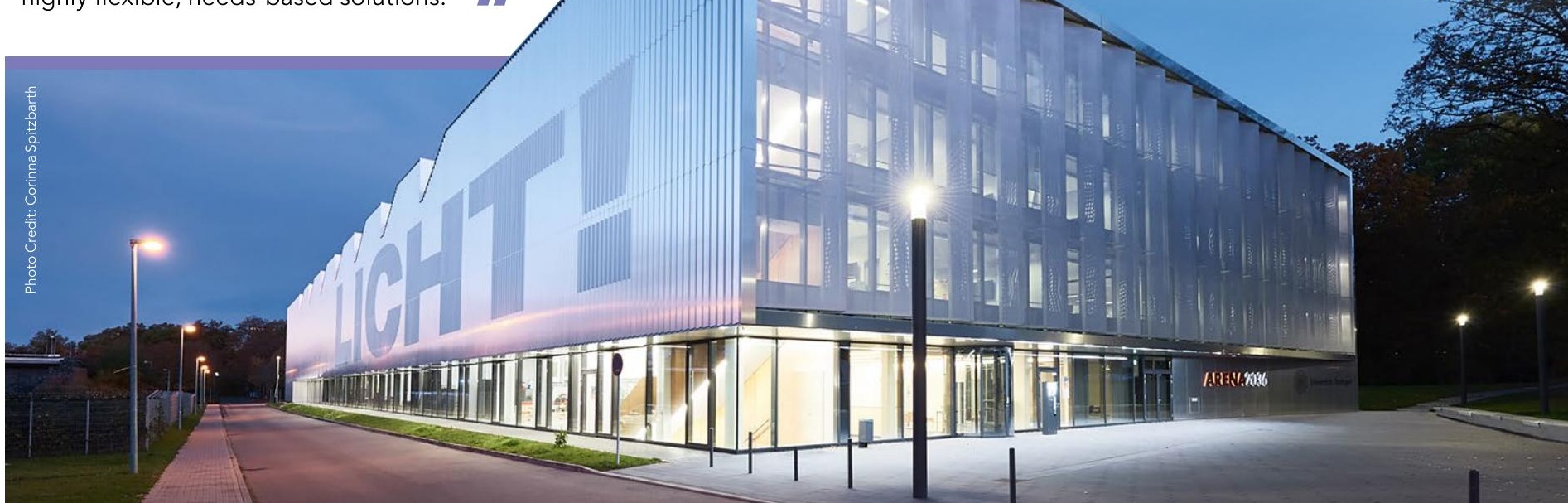

